\title{
Investigating the Therapeutic Potential of a Probiotic in a Rat Model for Infection Following Fracture Fixation
}

\author{
Mohsen Sadeghi-Naini, ${ }^{1,2}$ Mohammadsadegh Sabagh, ${ }^{2}$ Amirhossein Yamini, ${ }^{3}$ Farrokh Nakhjavani, ${ }^{4}$ \\ Babak Siavashi, ${ }^{1,5,}{ }^{*}$ and Caroline B Hing ${ }^{6}$ \\ ${ }^{1}$ Sina Trauma and Surgery Research Center, Tehran University of Medical Sciences, Tehran, Iran \\ ${ }^{2}$ Multidisciplinary Orthopedic and Rheumatologic Research Association, Tehran University of Medical Sciences, Tehran, Iran \\ ${ }^{3}$ Department of Medical Virology, Tarbiat Modares University, Tehran, Iran \\ ${ }^{4}$ Associate Professor of Microbiology, Department of Microbiology, Tehran University of Medical Sciences, Tehran, Iran \\ ${ }^{5}$ Department of Orthopedic Surgery, Sina Hospital, Tehran University of Medical Sciences, Tehran, Iran \\ ${ }^{6}$ Consultant Trauma and Orthopaedics, Department of Orthopaedic Surgery, St George's Hospital, London, UK \\ "Corresponding author: Babak Siavashi, Sina Trauma and Surgery Research Center, Tehran University of Medical Sciences, Tehran, Iran. E-mail: siavashi@tums.ac.ir
}

Received 2016 June 28; Revised 2016 September 24; Accepted 2016 November 12.

\begin{abstract}
Background: Staphylococcus aureus (S. aureus) is the most common pathogen responsible for osteomyelitis.

Objectives: Our objective was to investigate the potential of a probiotic as a treatment for S. aureus-induced infection following fracture fixation in a rat model.

Methods: Fifty male Sprague-Dawley rats were assigned to five groups (Control, S. aureus, S. aureus +ceftriaxone, S. aureus + once weekly probiotic, and S. aureus + twice weekly probiotic). Lactobacillus casei subsp. casei(ATCC:39392) was selected from eight strains of probiotic bacteria with anti-staphylococcal activity. Infection was induced by inoculation with106 colony-forming units (CFU) of S. aureus in a closed femur fracture model stabilized with an intramedullary pin. Three weeks after the surgery, the development of infection and response to the therapy was documented using radiographs, microbiological and histopathological analysis.

Results: No bacteria were recovered from rats in the Control group. The analysis of variance revealed a significant difference in the $\mathrm{CFU} / \mathrm{femur}(\mathrm{P}<0.001)$ and $\mathrm{CFU} / \mathrm{pin}(\mathrm{P}=0.001)$ across all five treatment groups. When the results were compared, the $\mathrm{CFU} / \mathrm{femur}$ was significantly lower in the $S$. aureus + Probiotic twice weekly in comparison with S. aureus $(\mathrm{P}=0.008)$ and the $S$. aureus + ceftriaxone $(\mathrm{P}=0.012)$ groups. Repeated measure ANOVA to test the radiographic scores during the follow-up time between the intervention groups revealed no significant differences $(\mathrm{P}=0.179)$.

Conclusions: Parenteral administration of viable L. casei inhibits S. aureus-induced infection as shown by the bacteriologic analysis, but makes no difference to the radiological union rates. This could be the first step towards developing an effective, biologic adjunctive therapy for the management of osteomyelitis following fracture fixation.
\end{abstract}

Keywords: Osteomyelitis, Fracture, Staphylococcus aureus, Probiotic, Lactobacillus casei

\section{Background}

Osteomyelitis is an inflammatory process of bone with resultant destructive and necrotic change accompanied by new bone formation, which can progress to a chronic or persistent stage (1). The incidence of osteomyelitis differs according to the primary inoculation and the underlying disease with a range of $1 \%$ to $15 \%(2,3)$. Rubin evaluated 1,351,362 non-obstetric hospital discharges in New York city hospitals in 1995 and showed that an estimated 2000 (0.00147) were patients with S. aureus osteomyelitis with an average hospital stay estimated to be 23.9 days with subsequent incurred costs of 35000 dollars indicating a significant burden to the health economy (4). S. aureus is the most common pathogen responsible for both acute and chronic forms of osteomyelitis $(1,5,6)$. S. aureus has developed a plethora of strategies to evade the host innate and adaptive immune systems, with a high resistance to different therapeutic options (7). Tice et al. in a long-term follow-up study of osteomyelitis treated in the outpatient setting found that $31 \%$ of 452 patients had recurrent infection, most within one year of occurrence (8).

Stengel et al. in a systematic review with meta-analysis of antibiotic therapy for osteomyelitis reported that the penetration of an antibiotic agent into an infected bone is determined by the pharmacological characteristics of the drug, degree of vascularization, soft-tissue coverage and the presence of a foreign body (9). To overcome the limited penetration of the systemic agents into poorly vascularized bone, systems for local delivery of antibiotics have been implemented in the previous studies $(10,11)$. Bucholz and Engelbrecht introduced the delivery of high-dose antibiotics to the skeletal tissues by resin (Palacos) in 1970

Copyright ( 2016, Sports Medicine Research Center. This is an open-access article distributed under the terms of the Creative Commons Attribution-NonCommercial 4.0 International License (http://creativecommons.org/licenses/by-nc/4.0/) which permits copy and redistribute the material just in noncommercial usages, provided the original work is properly cited. 
(12). Bone cement $(13,14)$ and polymethylmethacrylate (PMMA) beads (15) are other skeletal drug-delivery systems commonly used for this purpose. However, all of these techniques are static in nature with the potential of bacterial resistance.

Probiotics are viable cell preparations that have beneficial effects (16). Different strains of probiotics have different strategies to compete with S. aureus. Probiotic has been used in the treatment of many clinical infections in the middle ear, bladder, gut and the vagina of the humans and in the wounds of the animals (17-20). Since some probiotics are a dynamic source of antimicrobial agent with variable strategy, we hypothesized that specific probiotic strains of lactobacilli with predefined anti-infective properties against $S$. aureus could inhibit S. aureus-induced osteomyelitis. We, therefore, implemented an infection model following trauma fixation and investigated the therapeutic potential of the probiotics. A successful therapeutic strategy at this stage of trauma comprising an infected fracture with metalwork in situ would prevent the further development of infection in critically ill patients and allow the retention of fixation until osseous union occurs.

\section{Methods}

\subsection{Study Design}

Fifty male Sprague-Dawley rats were assigned to five groups:

Control (pinned femur fracture $+0.1 \mathrm{~mL}$ Phosphate buffered saline (PBS))

S. aureus (pinned femur fracture $+0.1 \mathrm{~mL}$ of $S$. aureus)

S. aureus +ceftriaxone (pinned femur fracture $+0.1 \mathrm{~mL}$ of $S$. aureus + ceftriaxone (50 mg/kg) every 24 hours for 3 weeks)

S. aureus + once weekly probiotic (pinned femur fracture $+0.1 \mathrm{~mL}$ of $S$. aureus $+0.1 \mathrm{~mL}$ Lactobacillus (LAD) every week for three weeks)

S. aureus + twice weekly probiotic (pinned femur fracture $+0.1 \mathrm{~mL}$ of $S$. aureus $+0.1 \mathrm{~mL}$ LAD twice weekly for three weeks)

The rats were humanely euthanized three weeks after the surgery with a lethal dose of Xylazine. The development of osteomyelitis was documented using radiographs (all animals), postmortem microbiological ( $\mathrm{n}=8$ per group) and histopathological ( $n=1$ per group) analysis. The study protocol was approved by the ${ }^{* * * *}$ animal care and use committee (date of approval: 29.1.2010, Code number: 16).

\subsection{Bacterial Preparation}

\subsubsection{Bacterial Strains}

Eight strains of LAD and five strains of staphylococcus were purchased from the Iranian research organization for science and technology (IROST). These strains were selected due to their potential effect against $S$. aureus in the previous studies $(18,21-25)$.

\subsubsection{Antimicrobial Activity}

The antibiotic susceptibility of all isolated strains was tested based on the standard methodology recommended by the Canadian committee on antibiotic resistance (26). A modified Coconnier model (27) was used to assess the antibacterial activity of each LAD with a modified "spot on the lawn" method described by Navarro (28). Based on the antibacterial activity of each LAD, Lactobacillus casei subsp. casei (ATCC: 39392 ) was the most potent probiotic against $S$. aureus, subsp. aureus (ATCC: 33591) and was selected for the rest of the study.

\subsection{Surgical Procedure}

The surgical procedure was a modification of that outlined in detail by Skott et al. (29). Each rat was anesthetized using intraperitoneal injections of ketamine (100 - $200 \mathrm{mg} / \mathrm{kg}$ ) and xylazine (2.0 - $4.0 \mathrm{mg} / \mathrm{kg})$. The right femur was prepared aseptically and a 20-gauge needle was used to create an entry port into the distal aspect of the medullary canal of the femur which was reamed to allow the insertion of the intramedullary pin. An inoculation dose of $0.1 \mathrm{~mL}$ of staphylococcus suspension $\left(10^{6}\right.$ bacteria) was slowly injected into the medullary cavity in the experimental groups, and in the control group PBS was injected instead.

A sterile stainless steel Kirschner wire, $1 \mathrm{~mm}$ in diameter and $20 \mathrm{~mm}$ in length was then inserted into the medullary canal and seated in the cortical bone in the proximal aspect of the femur. Thereafter, a mid-shaft closed fracture of the right femur was created using a specifically designed fracture apparatus that consisted of a blade which was placed in contact with the femur to fracture the femoral cortex before rotating the femur and fracturing the remainder of the cortex.

\subsection{Treatment Procedure}

We defined two time intervals for the probiotic injection to assess the dose-response effect. Rats in the $S$. aureus + probiotic group received $0.1 \mathrm{~mL}$ Lactobacillus casei subsp. casei $\left(10^{6} \mathrm{CFU}\right.$ in $\left.0.1 \mathrm{~mL}\right)$ once or twice weekly starting 24 hours after the inoculation, via two sub-periosteal injections near the fracture site for the duration of the study (three weeks). The $S$. aureus + ceftriaxone group received 
ceftriaxone (50 mg/kg) every 24 hours, starting 4 hours after the inoculation, via a subcutaneous injection for the duration of the study.

\subsection{Radiographic Assessment of Osteomyelitis}

Lateral radiographs of the right hind limb were obtained at weeks one, two, and three postoperatively. Two individuals (BS, $\mathrm{CH}$ ) evaluated the radiographs focusing on three regions of interest (RoI):

(1) Proximal metaphyseal area

(2) Diaphyseal region involving the site of the fracture

(3) Distal metaphyseal area

Each radiograph was assessed based on a validated system used by Lucke et al. $(30,31)$. The following radiographic changes were estimated for each ROI:(1) osteolysis, (2) soft tissue swelling, (3) periosteal reaction, (4) general impression and (5) deformity. The changes were given a score corresponding to the following scale: 0 - absent, 1 - mild, 2 moderate, or 3 - severe. For the general impression evaluation, a 0 represented a normal appearing femur/fracture and 3 represented severe changes present overall. In addition, sequestra formation (6) and spontaneous fracture (7) were evaluated for each femur as a whole and were awarded a score of 0 - absent or 1 - present. The scores were then summated with the highest possible total score being 47. The mean scores from the two evaluators were used for the statistical evaluation.

\subsection{Recovery of Bacteria}

Three weeks after the surgery, the femora of the right hind legs were dissected free from the underlying tissue under sterile conditions. The K-wires were aseptically retrieved from the operated femora prior to the snap freezing. Under sterile conditions, the K-wires were placed in $2.0 \mathrm{~mL}$ of sterile PBS, then spun for five minutes and centrifuged (10,000 RPM for 10 seconds) to dislodge adherent bacteria. A hundred micro liter samples were then collected for the microtiter dilution and the results were used to calculate the CFU/pin.

Each femur was snap frozen and ground to powder under sterile conditions. A hundred and fifty milligrams of the bone powder was agitated in $1.5 \mathrm{~mL}$ of sterile PBS for 2 minutes by vortex (3000 RPM) and the suspension was centrifuged for 10 seconds (10,000 RPM). A hundred microliters of the supernatant was withdrawn for serial dilution and sampled for microtiter dilutions to calculate the CFU/femur.

\subsection{Microtiter Dilution and Viable Bacterial Counts}

The CFU was determined in quadruplicate by collecting an aseptic sample. Tenfold dilutions were made $\left(10^{-1}\right.$ to $10^{-2}$ ) using PBS. Twenty microliters was streaked across a Trypticase Soy Agar (TSA) (Beckton Dickinson Diagnostic Systems, Sparks, MD) plate. The plates were then incubated aerobically at $37^{\circ} \mathrm{C}$ for 24 hours at which time the number of colonies was counted. Dilutions with up to 30 colonies present were used to calculate the median $\mathrm{CFU} /$ pin or $\mathrm{CFU} /$ femur. A sample was taken from each media plate to perform DNase, coagulase, catalase and novobiosin tests, in addition to culturing it in specific media to verify the specificity of colonies similar in shape and color.

\subsection{Histopathologic Evaluation}

The operated femur from one rat in each group was used for histopathologic evaluation. The sections were evaluated by a clinical pathologist who was blinded to the treatment group. Slices of the same osseous plane were evaluated based on the following parameters of infection in accordance with Petty and coworkers (32): 1) abscess formation, 2) sequestrum formation, 3) cortical enlargement, 4) cortical destruction, 5) general impression.

\subsection{Statistical Analysis}

Based on the results of Lucke's study (30), difference and standard deviation of 50000 and 80000 CFU per gram of bone were assumed for calculating sample size, respectively. In a one-way analysis of variance (ANOVA) study, sample sizes of eight animals in each group achieved $81 \%$ power to detect the differences among the means versus the alternative of equal means using an F test with a 0.05 significance level (33).

Kolmogorov-Smirnov test was used to determine if the data exhibited a normal distribution. The radiographs were scored by two independent orthopaedic surgeons anonymously. Intraclass correlation coefficients (ICC) were calculated to check the inter-observer reliability. The radiographic results were averaged and compared using the repeated measure ANOVA. If there was a missing follow-up, its value was calculated from the mean of nearby points. The recovered CFU/pin and CFU/femur were reported as mean CFU and were compared across all five groups using the ANOVA, with significance set at $\mathrm{P}<0.05$. The distributions of CFU/pin or CFU/femur were compared for each pair of treatment groups using the Scheffe posthoc test with significance set at $\mathrm{P}<0.05$. All the analyses were performed using the IBM SPSS Statistics Standard 20.0 (Chicago, IL, USA).

\section{Results}

\subsection{Radiographic Assessment}

At the third week postoperatively, the fracture was most evident in the S. aureus group, followed by the $S$. au- 
reus + ceftriaxone group, but was only weakly evident in the control and probiotic groups. The radiographs from the control group were characterized by callus formation limited to the fracture site. There was also a periosteal reaction in the control group accompanying the newly formed bone which represented the continuation of the healing process. The S. aureus group was characterized by extensive periosteal reaction extending throughout the femoral length. New bone formation beside the periosteal reaction in the S. aureus group did not bridge the fracture site and was accompanied by osteolysis along the femur. The S. aureus + ceftriaxone group was characterized by limited periosteal reaction along with new bone formation which bridged the fracture site. The S. aureus + Probiotic once weekly group was characterized by mild periosteal reaction with new bone formation that bridged the fracture site. There was no evidence of osteolysis in this group. The S. aureus + Probiotic twice weekly group was characterized by minor periosteal reaction and cortical thickening without any evidence of a fracture line (Figure 2).

Intra-class correlation coefficients (ICC) for the interobserver reliability of the radiographic scores in weeks one, two and three were $0.52,0.45$ and 0.59 , respectively. The Kolmogorov-Smirnov test revealed a normal distribution of this variable $(P=0.2)$. The radiographic scores at week one were similar in all of the five treatment groups (ANOVA, $\mathrm{P}=0.62$ ). The repeated measure ANOVA to test the radiographic scores during the follow-up time between the intervention groups revealed no significant differences throughout the follow-up period $(\mathrm{P}=0.179)$ (Figure 3).

\subsection{Recovery of Bacteria}

No bacteria were recovered from rats in the control group. The ANOVA revealed a significant difference in the CFU/femur $(\mathrm{P}<0.001)$ and $\mathrm{CFU} / \mathrm{pin}(\mathrm{P}=0.001)$ across all five treatment groups. When the results of each arm of the study were compared pair-wise using the Scheffe post-hoc test, the CFU/femur was significantly lower in the S. aureus + Probiotic twice weekly group in comparison with the $S$. aureus $(\mathrm{P}=0.008)$ and the $S$. aureus + ceftriaxone $(\mathrm{P}=0.012)$ groups; the $\mathrm{CFU} / \mathrm{femur}$ was not significantly different between the S. aureus group compared with the S. aureus + ceftriaxone group $(\mathrm{P}=1.0)$ and the $S$. aureus + Probiotic twice weekly group compared with the $S$. aureus + Probiotic once weekly group $(\mathrm{P}=0.8)$. The $\mathrm{CFU} /$ pin results followed a similar pattern to $\mathrm{CFU} /$ femur. (Figure 4, Table 1)

\subsection{Histopathology}

The specimen from the control group was characterized by the presence of callus. In contrast, the specimen from the S. aureus group was characterized by active reactive bone and osteoid formation with fibrosis, extending to the marrow space and the cortex with encasement of callus including hyaline cartilage. Acute suppurative inflammation was seen which was enclosed in the reactive changes. The specimen from the S. aureus + Ceftriaxone group was characterized by the presence of severe and acute suppurative inflammation plus bone sequestrum (acute suppurative osteomyelitis) extending to the fracture site and the periosteal surface. There was a narrow rim of callus formation that was composed of hyaline cartilage at the periphery of the inflammation. The specimens from Probiotic groups were similar to that of S. aureus group except for more prominent fracture site callus formation in the probiotic once weekly group, and prominent bone sequestrum and infarct in the probiotic twice weekly group.

\section{Discussion}

The results of the present study revealed that viable Lactobacillus casei can inhibit acute infection caused by $S$. aureus. Although the histopathological deduction is limited due to inadequate histologic specimens, this assessment revealed that probiotic bacteria may slow down the healing process, in spite of improving the bacteriologic results. We could not deduct on the radiographic assessment due to the lack of significant difference between the intervention groups. This may be due to limited sample size or low inter-observer ICC. To our knowledge, this is the first study to demonstrate the administration of a viable probiotic strain through a parenteral route (subperiosteal) in the in vivo treatment of osteomyelitis.

Hospitals in the Europe link for infection control through surveillance (HELICS) have reported that $48.6 \%$ of surgical site infection secondary to orthopedic surgery was due to S. aureus (34). S. aureus adheres to fixation devices by producing a glycocalyx biofilm around prosthetic materials and forms large micro-colonies. The biofilm confers bacterial resistance to antibiotics and ingestion by neutrophils (6). Conversely, bone necrosis developing early in the disease process limits the possibility of eradicating the pathogen and leads to chronicity (35). Treatment strategies for osteomyelitis mainly consist of three stages, firstly antimicrobial agents, secondly surgical techniques and thirdly amputation (36). A variety of antimicrobial agents with a different spectrum of action, pharmacokinetics and pharmacodynamics have been used in this manner. Due to the physiological and anatomic characteristics of the bone, antimicrobial therapies are thus suboptimal in the treatment of osteomyelitis. Surgical techniques, including limb salvage, muscle grafts, Ilizarov techniques, antibiotic coated prostheses and antibiotic bone cement 


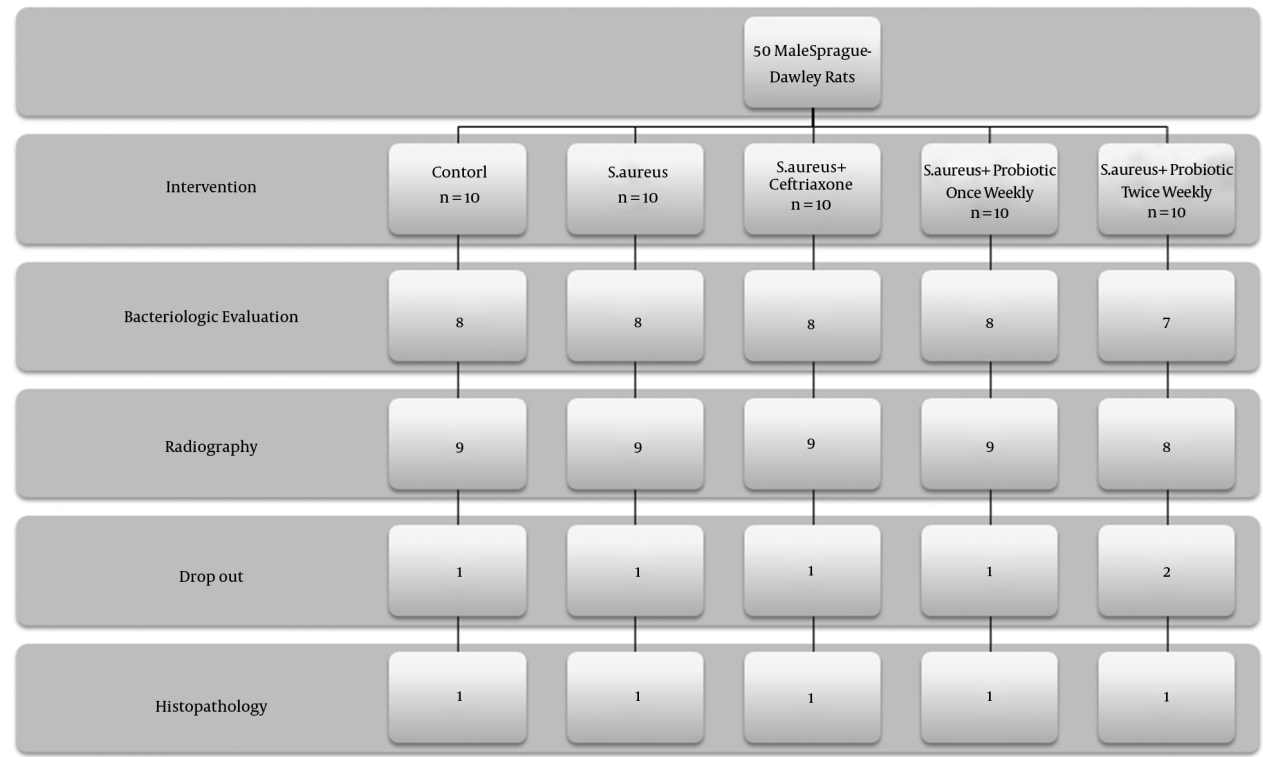

Figure 1. Flow Chart of Intervention Groups

1. Control

2.S. aureus

3. S. aureus + Ceftriaxone

4. S. aureus+ Probiotic Once Weekly

5. S. aureus+ Probiotic Twice Weekly
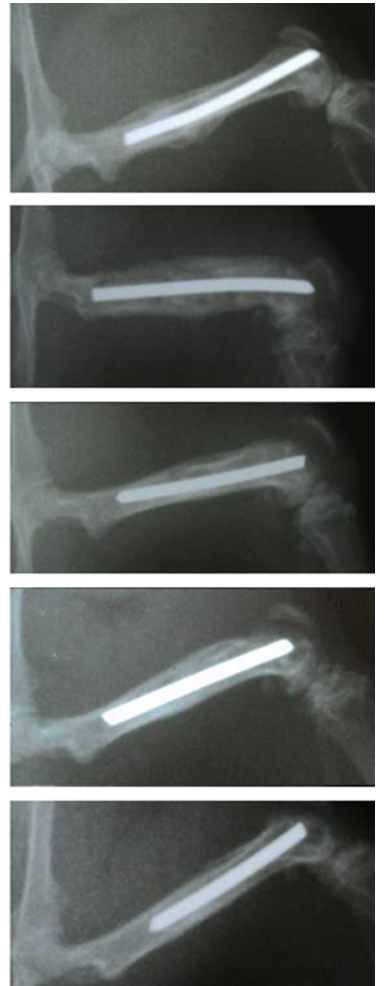

Figure 2. Representative Radiographs from a Rat in Each Group at 3 Weeks After Surgery

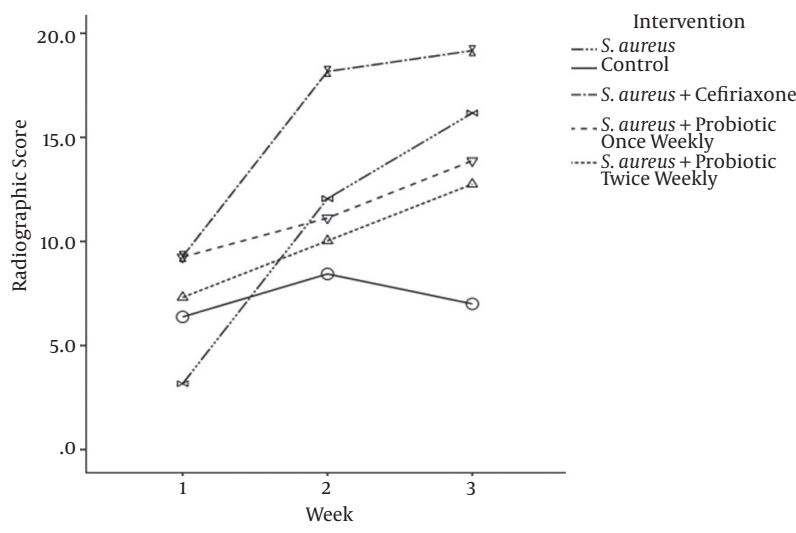

Figure 3. Radiographic Scores at One, Two and Three Weeks After Surgery

have also been applied with varying degrees of success (1, 36).

The definition of a Probiotic is: a live micro-organism which when administered in adequate amounts confers a health benefit to the host (FAO/WHO report, October, 2001). There are few studies that have assessed the parenteral administration of the probiotic. Sheil studied the parenteral administration of viable probiotic to alleviate mice induced colitis and arthritis (37). L. casei is a gram positive bacillus that ferments carbohydrates mainly to lactic acid which consequently leads to environmental acidification down to a pH of 3.5 (38). There are several hypotheses 


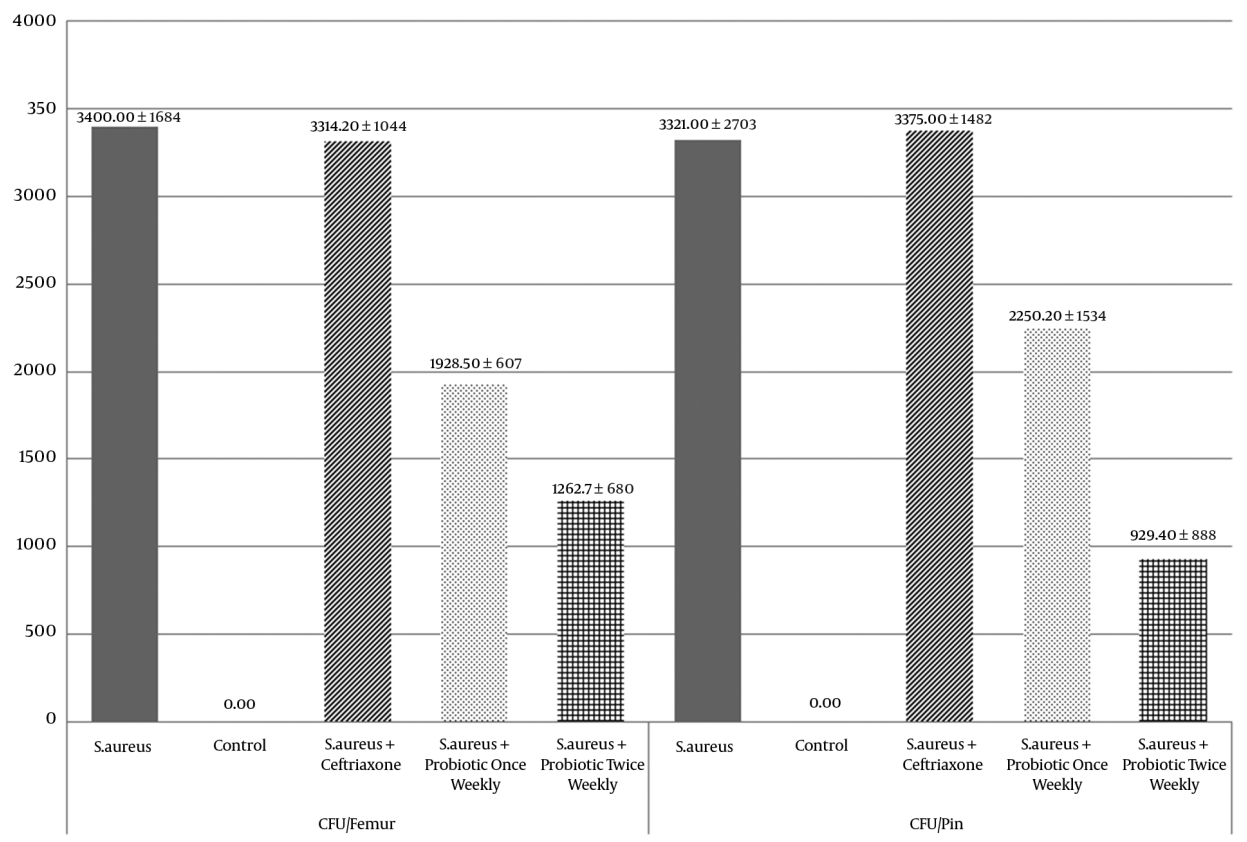

Figure 4. Colony Forming Units (CFU) Recovered from Each Femur and the Intramedullary Pin

regarding the mechanism involved in the inhibition process of $S$. aureus by $L$. casei. They include environmental acidification, production of hydrogen peroxide, production of bacteriocins and nutritional competition (38). Sadowska et al. showed that LAB could inhibit staphylococcal adhesion and slime layer production using bacteriocin and bacteriocin-like inhibitory substances (24). In addition, laboratory studies revealed that the acidification of a growth medium by addition of lactic acid down to $\mathrm{pH}$ 4.5 , completely inhibits the growth of $S$. aureus (38). The ratio of $S$. aureus against LAB is another determinant of the growth inhibition. Therefore, in media where the S. aureus population is larger than $\mathrm{LAB}$, the size of the $S$. aureus can reach $1010 \mathrm{CFU} / \mathrm{mL}$ (a level at which $S$. aureus begins enterotoxin production and limits its growth). However, for a S. aureus: LAB ratio of $1 / 1$ and $1 / 10$, maximum population reached by $S$. aureus is about $10^{6}$ and $10^{5} \mathrm{CFU} / \mathrm{mL}$, respectively (38).

Lactic acid bacteria are generally safe with limited clinical infections reported in the humans where LAB were the causative pathogen (39) and few case reports describe the isolation of LAB from patients with infective endocarditis, localized infection and septicemia $(40,41)$. Adams and Marteau (42) concluded that LAB posed no significant risk of infection if administered orally. There are few studies on the parenteral use of probiotic $(26,37,38,43)$. Therefore, ex- tending LAB safety to parenteral administration needs further study.

Our study has some limitations. Our experimental model does not exactly mirror the clinical scenario. Therefore, we cannot conclude that probiotic could be a treatment option for implant-related osteomyelitis. Meanwhile, this can be a new branch for potential treatment option in the future. Due to an executory problem in the radiology department, we could not radiograph one group ( $S$. aureus + Probiotic twice weekly) in week 2 and, therefore, inputted the missing data by averaging the radiographs in weeks 1 and 3. We also could not determine the exact mechanism of the inhibition of S. aureus by L. casei in vivo and vitro. In the bacteriologic evaluation, we used selective media for S. aureus where L. casei could not grow and confound the finding. In addition, we performed specificity tests to validate observed colonies as S. aureus and differentiate them from other similar colonies such as Streptococcus and other strains of Staphylococcus. In the histologic evaluation, the number of specimen from each intervention group was not adequate for statistical analysis. Therefore, we narratively described the histologic finding without statistical analysis.

In conclusion, parenteral administration of viable $L$. casei inhibits S. aureus-induced osteomyelitis as shown by bacteriologic analysis, but makes no difference to radio- 
Table 1. P Value of Scheffe Post-Hoc Test Compare CFU/Pin And CFU/Femur in Each Pair of Treatment Groups

\begin{tabular}{|c|c|c|c|c|c|}
\hline & Control & S. aureus & S. aureus + Ceftriaxone & $\begin{array}{c}\text { S. aureus + Once Weekly } \\
\text { Probiotic }\end{array}$ & $\begin{array}{c}\text { S. aureus + Twice Weekly } \\
\text { Probiotic }\end{array}$ \\
\hline \multicolumn{6}{|l|}{ CFU/Bone } \\
\hline Control & - & $<0.01^{*}$ & $<0.01^{*}$ & $0.02^{*}$ & 0.23 \\
\hline S. aureus & $<0.01^{*}$ & - & 1.00 & 0.12 & $<0.01^{*}$ \\
\hline S. aureus + ceftriaxone & $<0.01^{*}$ & 1.00 & - & 0.16 & $0.01^{*}$ \\
\hline $\begin{array}{l}\text { S. aureus + once weekly } \\
\text { probiotic }\end{array}$ & $0.02^{*}$ & 0.12 & 0.16 & - & 0.80 \\
\hline $\begin{array}{l}\text { S. aureus + twice weekly } \\
\text { probiotic }\end{array}$ & 0.23 & $<0.01^{*}$ & $0.01^{*}$ & 0.8 & - \\
\hline \multicolumn{6}{|l|}{ CFU/Pin } \\
\hline Control & - & $0.01^{*}$ & $<0.01^{*}$ & 0.16 & 0.87 \\
\hline S. aureus & $0.01^{*}$ & - & 1.00 & 0.80 & 0.12 \\
\hline S. aureus +ceftriaxone & $<0.01^{*}$ & 1.00 & - & 0.75 & 0.09 \\
\hline $\begin{array}{l}\text { S. aureus + once weekly } \\
\text { probiotic }\end{array}$ & 0.16 & 0.80 & 0.75 & - & 0.66 \\
\hline $\begin{array}{l}\text { S. aureus + twice weekly } \\
\text { probiotic }\end{array}$ & 0.87 & 0.12 & 0.09 & 0.66 & - \\
\hline
\end{tabular}

logic union rates. This could be the first step in developing an effective, safe and inexpensive treatment for osteomyelitis.

\section{Acknowledgments}

This study was supported by a grant from the Sina trauma and surgery research center (STSRC). We acknowledge Prof. Siamak Shams-shariat-Torghaban for his help in interpreting the histopathological specimens. We also acknowledge Dr. Khoshzaban, Ms. Aghazadeh and Ms. Aghajanpour for their help during the animal surgery phase.

\section{Footnotes}

Authors' Contribution: Study concept and design: Mohsen Sadeghi-Naini; acquisition of data: Mohsen Sadeghi-Naini, Mohammadsadegh Sabagh, Amirhossein Yamini and Farrokh Nakhjavani; analysis and interpretation of data: Mohsen Sadeghi-Naini; drafting of the manuscript: Mohsen Sadeghi-Naini; critical revision of the manuscript for important intellectual content: Babak Siavashi and Caroline B Hing; statistical analysis: Mohsen Sadeghi-Naini; administrative, technical, and material support: Farrokh Nakhjavani, Babak Siavashi; study supervision: Babak Siavashi

Competing Interests: We wish to confirm that there are no known conflicts of interest associated with this publication and there has been no significant financial support for this work which could have influenced its outcome.

\section{References}

1. Jorge LS, Chueire AG, Rossit AR. Osteomyelitis: a current challenge. Braz J Infect Dis. 2010;14(3):310-5. [PubMed: 20835519].

2. Longmore T. Remarks upon Osteo-myelitis consequent on Gunshot Wounds of the Upper and Lower Extremities, and especially upon the Treatment of Stumps affected with Osteomyelitis after Amputation necessitated by such Injuries. Med Chir Trans. 1865;48:43-64 1. [PubMed: 20896266].

3. Lew DP, Waldvogel FA. Osteomyelitis. Lancet. 2004;364(9431):369-79. doi: 10.1016/S0140-6736(04)16727-5. [PubMed: 15276398].

4. Rubin RJ, Harrington CA, Poon A, Dietrich K, Greene JA, Moiduddin A. The economic impact of Staphylococcus aureus infection in New York City hospitals. Emerg Infect Dis. 1999;5(1):9-17. doi: 10.3201/eid0501.990102. [PubMed: 10081667].

5. Sia IG, Berbari EF. Infection and musculoskeletal conditions: Osteomyelitis. Best Pract Res Clin Rheumatol. 2006;20(6):1065-81. doi: 10.1016/j.berh.2006.08.014. [PubMed: 17127197].

6. Saadatian-Elahi M, Teyssou R, Vanhems P. Staphylococcus aureus, the major pathogen in orthopaedic and cardiac surgical site infections: a literature review. Int J Surg. 2008;6(3):238-45. doi: 10.1016/j.ijsu.2007.05.001. [PubMed: 17561463].

7. Park B, Liu GY. Targeting the host-pathogen interface for treatment of Staphylococcus aureus infection. Semin Immunopathol. 2012;34(2):299-315. doi: 10.1007/s00281-011-0297-1. [PubMed: 22089960].

8. Tice AD, Hoaglund PA, Shoultz DA. Outcomes of osteomyelitis among patients treated with outpatient parenteral antimicrobial therapy. American J Med. 2003;114(9):723-8. doi: 10.1016/s0002-9343(03)002316.

9. Stengel D, Bauwens K, Sehouli J, Ekkernkamp A, Porzsolt F. Systematic review and meta-analysis of antibiotic therapy for bone and joint infections. Lancet Infect Dis. 2001;1(3):175-88. doi: 10.1016/S14733099(01)00094-9. [PubMed: 11871494] 
10. Seabrook GR, Edmiston CE, Schmitt DD, Krepel C, Bandyk DF, Towne JB. Comparison of serum and tissue antibiotic levels in diabetes-related foot infections. Surgery. 1991;110(4):671-6. [PubMed: 1925956] discussion 676-7.

11. Jain AK, Panchagnula R. Skeletal drug delivery systems. Int J Pharm. 2000;206(1-2):1-12. [PubMed: 11058805].

12. Buchholz HW, Engelbrecht H. [Depot effects of various antibiotics mixed with Palacos resins]. Chirurg. 1970;41(11):511-5. [PubMed: 5487941].

13. Ginebra MP, Traykova T, Planell JA. Calcium phosphate cements as bone drug delivery systems: a review. J Control Release. 2006;113(2):102-10. doi: 10.1016/j.jconrel.2006.04.007. [PubMed: 16740332].

14. Otsuka M, Matsuda Y, Yu D, Wong J, Fox JL, Higuchi WI. A novel skeletal drug delivery system for anti-bacterial drugs using self-setting hydroxyapatite cement. Chem Pharm Bull. 1990;38(12):3500-2. doi: 10.1248/cpb.38.3500.

15. Blaha JD, Calhoun JH, Nelson CL, Henry SL, Seligson D, Esterhai JJ, et al. Comparison of the clinical efficacy and tolerance of gentamicin PMMA beads on surgical wire versus combined and systemic therapy for osteomyelitis. Clin Orthop Relat Res. 1993(295):8-12. [PubMed: 8403674].

16. Lkhagvadorj E, Nagata S, Wada M, Bian L, Wang C, Chiba Y, et al. Anti-infectious activity of synbiotics in a novel mouse model of methicillin-resistant Staphylococcus aureus infection. Microbiol Immunol. 2010;54(5):265-75. doi: 10.1111/j.1348-0421.2010.00224.X. [PubMed: 20536723].

17. Valdez JC, Peral MC, Rachid M, Santana M, Perdigon G. Interference of Lactobacillus plantarum with Pseudomonas aeruginosa in vitro and in infected burns: the potential use of probiotics in wound treatment. Clin Microbiol Infect. 2005;11(6):472-9. doi: 10.1111/j.14690691.2005.01142.x. [PubMed: 15882197].

18. Gan BS, Kim J, Reid G, Cadieux P, Howard JC. Lactobacillus fermentum RC-14 inhibits Staphylococcus aureus infection of surgical implants in rats. J Infect Dis. 2002;185(9):1369-72. doi: 10.1086/340126. [PubMed: 12001060].

19. Reid G, Jass J, Sebulsky MT, McCormick JK. Potential uses of probiotics in clinical practice. Clin Microbiol Rev. 2003;16(4):658-72. [PubMed: 14557292].

20. Roos K, Hakansson EG, Holm S. Effect of recolonisation with "interfering" alpha streptococci on recurrences of acute and secretory otitis media in children: randomised placebo controlled trial. BMJ. 2001;322(7280):210-2. [PubMed:11159619].

21. Kim YG, Ohta T, Takahashi T, Kushiro A, Nomoto K, Yokokura T, et al. Probiotic Lactobacillus casei activates innate immunity via NF-kappaB and p38 MAP kinase signaling pathways. Microbes Infect. 2006;8(4):994-1005. doi: 10.1016/j.micinf.2005.10.019. [PubMed: 16513392]

22. Salinas I, Myklebust R, Esteban MA, Olsen RE, Meseguer J, Ringo E. In vitro studies of Lactobacillus delbrueckii subsp. lactis in Atlantic salmon (Salmo salar L.) foregut: tissue responses and evidence of protection against Aeromonas salmonicida subsp. salmonicida epithelial damage. Vet Microbiol. 2008;128(1-2):167-77. doi: 10.1016/j.vetmic.2007.10.011. [PubMed: 18054448].

23. Walencka E, Rozalska S, Sadowska B, Rozalska B. The influence of Lactobacillus acidophilus-derived surfactants on staphylococcal adhesion and biofilm formation. Folia Microbiol (Praha). 2008;53(1):61-6. doi:10.1007/s12223-008-0009-y. [PubMed: 18481220].

24. Sadowska B, Walencka E, Wieckowska-Szakiel M, Rozalska B. Bacteria competing with the adhesion and biofilm formation by Staphylococcus aureus. Folia Microbiol (Praha). 2010;55(5):497-501. doi: 10.1007/s12223-010-0082-x. [PubMed: 20941586].

25. Xu H, Jeong HS, Lee HY, Ahn J. Assessment of cell surface proper- ties and adhesion potential of selected probiotic strains. Lett Appl Microbiol. 2009;49(4):434-42. doi: 10.1111/j.1472-765X.2009.02684.X. [PubMed: 19725886]

26. Peral MC, Martinez MA, Valdez JC. Bacteriotherapy with Lactobacillus plantarum in burns. Int Wound J. 2009;6(1):73-81. doi: 10.1111/j.1742481X.2008.00577.x. [PubMed: 19291120].

27. Coconnier MH, Lievin V, Bernet-Camard MF, Hudault S, Servin AL. Antibacterial effect of the adhering human Lactobacillus acidophilus strain LB. Antimicrob Agents Chemother. 1997;41(5):1046-52. [PubMed: 9145867].

28. Navarro L, Zarazaga M, Saenz J, Ruiz-Larrea F, Torres C. Bacteriocin production by lactic acid bacteria isolated from Rioja red wines. J Appl Microbiol. 2000;88(1):44-51. [PubMed:10735242].

29. Skott M, Andreassen TT, Ulrich-Vinther M, Chen X, Keyler DE, LeSage MG, et al. Tobacco extract but not nicotine impairs the mechanical strength of fracture healing in rats. J Orthop Res. 2006;24(7):1472-9. doi: 10.1002/jor.20187. [PubMed: 16705735].

30. Lucke M, Schmidmaier G, Sadoni S, Wildemann B, Schiller R, Stemberger A, et al. A new model of implant-related osteomyelitis in rats. J Biomed Mater Res B Appl Biomater. 2003;67(1):593-602. doi 10.1002/jbm.b.10051. [PubMed:14528456].

31. Lucke M, Schmidmaier G, Sadoni S, Wildemann B, Schiller R, Haas $\mathrm{NP}$, et al. Gentamicin coating of metallic implants reduces implantrelated osteomyelitis in rats. Bone. 2003;32(5):521-31. [PubMed: 12753868].

32. Petty W, Spanier S, Shuster JJ, Silverthorne C. The influence of skeletal implants on incidence of infection. Experiments in a canine model. $J$ Bone Joint Surg Am. 1985;67(8):1236-44. [PubMed: 3902846].

33. Fleiss JL. Design and analysis of clinical experiments. 73. John Wiley \& Sons; 2011.

34. Wilson J, Ramboer I, Suetens C. Hospitals in Europe Link for Infection Control through Surveillance (HELICS). Inter-country comparison of rates of surgical site infection - opportunities and limitations. J Hosp Infect. 2007;65:165-70. doi:10.1016/s0195-6701(07)60037-1.

35. Calhoun JH, Manring MM. Adult osteomyelitis. Infect Dis Clin North Am 2005;19(4):765-86. doi:10.1016/j.idc.2005.07.009. [PubMed: 16297731]

36. Bose D, Kugan R, Stubbs D, McNally M. Management of infected nonunion of the long bones by a multidisciplinary team. Bone Joint J. 2015;97-B(6):814-7. doi: 10.1302/0301-620X.97B6.33276. [PubMed: 26033062].

37. Sheil B, McCarthy J, O'Mahony L, Bennett MW, Ryan P, Fitzgibbon JJ, et al. Is the mucosal route of administration essential for probiotic function? Subcutaneous administration is associated with attenuation of murine colitis and arthritis. Gut. 2004;53(5):694-700. [PubMed: 15082588]

38. Charlier C, Cretenet M, Even S, Le Loir Y. Interactions between Staphylococcus aureus and lactic acid bacteria: an old story with new perspectives. Int J Food Microbiol. 2009;131(1):30-9. doi: 10.1016/j.ijfoodmicro.2008.06.032. [PubMed: 18687499].

39. Aguirre M, Collins MD. Lactic acid bacteria and human clinical infection. J Appl Bacteriol. 1993;75(2):95-107. [PubMed: 8407678].

40. Ishibashi N, Yamazaki S. Probiotics and safety. Am JClin Nutr. 2001;73(2 Suppl):465S-70S. [PubMed: 11157359].

41. Gasser F. Safety of lactic acid bacteria and their occurrence in human clinical infections. Bulletin de l'Institut Pasteur. 1994;92(1):45-67.

42. Adams MR, Marteau P. On the safety of lactic acid bacteria from food Int J Food Microbiol. 1995;27(2-3):263-4. [PubMed: 8579995].

43. Vankerckhoven V, Moreillon P, Piu S, Giddey M, Huys G, Vancanneyt M, et al. Infectivity of Lactobacillus rhamnosus and Lactobacillus paracasei isolates in a rat model of experimental endocarditis. J Med Microbiol. 2007;56(Pt 8):1017-24. doi: 10.1099/jmm.0.46929-0. [PubMed 17644707]. 